\title{
UTTERANCE-FINAL CONJUNCTIVE PARTICLES AND IMPLICATURE IN JAPANESE CONVERSATION
}

\author{
Michael Haugh
}

\begin{abstract}
According to the received view, connective particles are characterised as "bound grammatical markers" that connect two clauses into a 'sentence' (Matsumoto, Yo 1988: 345). As Fukushima (2005) points out though, these conjunctions have other functions that go beyond intra-sentential usage. Utterance-final conjunctive particles have been analysed thus far, for the most part, as a type of (clausal) ellipsis or as particles that give rise to various pragmatic effects. In this paper, it is suggested that an approach to utterance-final conjunctive particles that is grounded in the notion of implicature may offer a complementary perspective on this phenomenon. The notions of "(im)politeness implicature" and "interactional implicature" are utilised in order to discuss how utterance-final conjunctive particles may trigger inferences leading to various interpersonal and interactional effects. By carefully analysing the projection and uptake of these implicatures apparent in the sequential development of interpretings conjointly co-constituted in Japanese conversation, it is argued that the analysts' and participants' perspectives can be better reconciled to avoid the imposition of an analysis by the researcher which is not contingently relevant to those participants. It is argued that through such an analysis the manner in which linguistic and communicative perspectives on implicature can complement one another can be explored more fully.
\end{abstract}

Keywords: Japanese; Conjunction; Implicature; (Im)politeness; Interactional achievement; Pragmatic analysis.

\section{Introduction}

A number of conjunctions which are attached to clauses to form subordinate clauses can occur in the utterance-final position in Japanese conversation. These are termed 'connective particles' (setsuzoku-joshi) in order to differentiate them from 'connectives' (setsuzoku-shi), which canonically occur in the clause-initial position to connect distinct 'sentences'. Connective particles are traditionally analysed as variously indicating a cause or reason for an action or attitude described in the main clause (kara/node, 'because', 'so'), the expression of opposing or disjunctive ideas (kedo/ga, 'although', 'but'), or that the fulfillment of the action or state in the main clause is conditional upon the action or state expressed in the subordinate clause (tara/ba/to, 'if'). According to the received view, then, connective particles are "bound grammatical markers" that connect two clauses into a 'sentence,' and thus operate in the domain of syntax (Matsumoto, Yo 1988: 345). It is widely recognised, however, that these subordinate clauses do not always have to be immediately preceded or followed by a 'main' clause, particularly in 
spoken Japanese (Iguchi 1998: 99). In the utterance-final position these conjunctive particles have other functions that go beyond canonical intra-sentential usage as traditionally outlined in the literature. One of the functions of the connective particle $g a$, for example, is as an "assertion softener" to show politeness (Fukushima 2005: 83-86). Other researchers have described further interpersonal and interactional functions of utterance-final conjunctive particles, including minimising speaker accountability for what is said, indicating intimacy or power, showing emotion, and signaling topic-shift or offering a speaking turn (Okamoto 1985: 215; Tanaka 2004: 86).

Their status as utterance-final conjunctive particles, rather than intra-sentential conjunctives, is generally marked through various linguistic and paralinguistic cues, including falls in pitch, pausing, prolonged syllables, weaker voice, interactional particles of confirmation (ne and $s a$ ), and other non-verbal signals (eye contact or sharp nod) (cf. Hinds 1978: 105-106; Maynard 1989: 145-146; Yoneha 2003: 82). For example, in the following extract where a couple are discussing the possibility of going on a trip, the conjunctive particle kara is marked as being in the utterance-final position through Kazuo's weaker voice in uttering it, and short pause that follows it. ${ }^{1}$

(1) (Kana and Kazuo are a married couple. Kana wants them to go on a trip before Kazuo's mother, younger brother and wife come to visit them from Japan)

1 Kana: Sono mae madeni dokoka it-te-ko-nai to. that before by somewhere go-Te-come-Neg if (We should go somewhere before that.)

2 Kazuo: [weak voice] $U n$.

3 Kana: Ryokō.

(Yeah.)

4 Kazuo:[weak voice] Un. Zeni ga nai kara...[short pause] yeah money Nom not so

5 Kana: Ja, furorida ni shi-te-mi-nai? (Yeah, we don't have [much] money so...) then Florida to do-Te-try-Neg (Then, why don't we try Florida?) (adapted from Okazaki 1994: 245)

In this example, Kazuo implies in line 4 that they cannot afford an expensive trip (that is, overseas), which is evident from Kana's response in line 5 where she suggests they try Florida or somewhere else within the United States. In doing so, Kazuo mitigates the illocutionary strength of this assertion by leaving its potentially confrontational content unsaid, as well as emphasising the reason for his viewpoint. He also offers the speaking turn to Kana, thereby attempting to minimize his responsibility for the implied conclusion, an offer which Kana subsequently takes up in line 5.

Numerous studies have indicated that utterance-final conjunctive particles are commonly exploited by speakers of Japanese to give rise to such interpersonal and interactional meanings (Mori 1999; Okamoto 1985; Tanaka 1999, Tanaka 2004; Usami 2002). Tanaka (2004: 82), for example, found that $28 \%$ of utterances in her corpus gathered from recordings of a Japanese television talk show were "unfinished examples.

${ }^{1}$ See Appendix A for a list of abbreviations used in the morphological glosses of the following 
utterances", while Tanaka (1999: 220) found around 12\% of utterances in her corpus of naturally occurring conversational data were "syntactically incomplete". While the proportion of utterance-final conjunctive particles varies to some degree across different interactional genres, it is apparent that they constitute an important element in Japanese conversation. It is thus unsurprising that they have been the focus of considerable attention by researchers to date.

Utterance-final conjunctive particles have been analysed thus far, for the most part, as either a type of (clausal) ellipsis (Hubbard 1998; Maynard 1989; Ooishi 1981; Okamoto 1985; Okazaki 1994; Takahashi 1993; Tanaka 2004; Uchito 1997; Yoneha Okazaki 2003), or as 'sentence-final particles' that show relationships between utterances across turns in discourse (Iguchi 1998; Mori 1999; Tanaka 1999), give rise to pragmatic effects (Fujita 2001: 137-142; Itani 1992; Kamio 1994: 80; Mori 1999; Nakayama and Ichihashi-Nakayama 1997: 612-613; Ohori 1995: 208-211; Tanaka 1999; $\mathrm{Xu}$ 2002; Yamaguchi 2007: 189-190), as well as inviting turn-taking (Ohori 1995: 203; Mori 1999; Tanaka 1999). An important finding arising in a number of these studies, however, is that while utterance-final conjunctive particles are often syntactically "incomplete," in the flow of actual conversational interaction they are contingently treated as complete turns by participants (Tanaka 1999: 219). They have also raised the issue of just how these particles give rise to these various pragmatic effects.

In this paper, building upon the observation that utterance-final conjunctive particles may achieve various interpersonal and interactional effects through implicatures (Fukushima 2005: 83-86; Iguchi 1998: 113-114; Obana 2000: 295-301), it is proposed that an approach grounded in the notion of 'implicature', where something is understood by participants to have been implied in addition to what is literally said, might allow us to more carefully examine the manner in which these pragmatic effects arise. It is also suggested that where implicatures can be shown to be contingently relevant to participants in interaction, we may be able to more successfully reconcile the analysts' and participants' perspectives on utterance-final conjunctive particles. This paper begins by first outlining ellipsis-based approaches to utterance-final conjunctive particles in Japanese, as well as approaches which conceptualise them as sentence-final or pragmatic particles, before describing how this phenomenon might be re-visited using the notion of implicature.

\section{Previous approaches to utterance-final conjunctive particles in Japanese}

\subsection{The ellipsis approach}

Utterance-final conjunctive particles in Japanese have commonly been treated as a form of (clausal) ellipsis, as scholars have expanded the research program from early studies of syntactic ellipsis (Kuno 1978; Hinds 1982) to the omission of other units that are not precisely recoverable from broader contextual information (Kabaya 1993; Maynard 1989; Ooishi 1981: 47-48; Okamoto 1985; Okazaki 1994; Takahashi 1993; Tanaka 2004; Uchito 1997; Yoneha Okazaki 2003). Ellipsis in this broader sense is defined by Yoneha Okazaki (2003) as "the non-presence of entities in surface forms of utterances which the speaker assumes that the hearer can fill in from linguistic and/or extralinguistic contexts" (p.80). However, as Okamoto (1985) notes, this "does not 
presuppose the existence of a particular underlying lexical form and its deletion" (p.108), as while the meaning of an elliptical utterance might be vaguer, it may also be more "inclusive" and have other pragmatic effects than those of a "particular lexical 'full' form" (p.109). The focus of the ellipsis-based approach to utterance-final conjunctives, then, has primarily been on the functions of (clausal) ellipsis in conversation. In this section, the two most comprehensive studies of utterance-final conjunctive particles from the perspective of ellipsis are discussed in more detail.

Okamoto's (1985) seminal study was groundbreaking in its detailed explication of the various functions verbal and clausal ellipsis in Japanese. In her study, Okamoto described how ellipsis, which she defines as "the non-lexicalisation of (i.e. nonapplication of any verbal or clause for) a certain (semantic) item in the situation described in the utterance," (p.108) has a number of functions in the expression of various speech acts. The most important of these was argued to be the "satisfaction of politeness" (pp.113-114), a finding which is supported by numerous other studies that have cited 'politeness', or more generally rapport and involvement, as one motivation for ellipsis in Japanese (Fukushima 2005: 86; Kabaya 1993: 27-28; Mizutani and Mizutani 1987: 26-29; Obana 2000: 296-300; Ooishi 1981; Ooyama 1998; Takahashi 1993; Tanaka 2004: 86; Toyada and Ishihara 2003: 213; Uchito 1997; Won 1999; Yoneha 2003: 87). While Okamoto (1985: 215) argued that other functions of ellipsis should not be ignored, including the avoidance of responsibility, showing intimacy or power, expressing emotion, and catching the attention of others, the vast majority of examples she cited to validate these latter functions involved instances of verbal ellipsis rather than utterance-final conjunctive particles per se. The key finding from Okamoto's (1985) study for the analysis of utterance-final conjunctive particles, then, was that their usage can give rise to politeness "by indicating that what is overtly expressed is not all that the speaker wants to say" (ibid.: 130), thereby mitigating the illocutionary strength of assertions, complaints, requests, refusals and the like. ${ }^{2}$ Yet while Okamoto's (1985) study was comprehensive in its scope, it remained somewhat speculative in that it relied to a large extent on "intuitive data" where the recipient's uptake was generally not considered in the analysis, thereby focusing only on what was potentially "projected" by the speaker through the usage of utterance-final conjunctive particles. It is also notable that while they were treated as examples of clausal ellipsis, in her actual explications, Okamoto (1985) made repeated reference to the notions of implying and implicature. It is thus not entirely clear why she chose to treat this phenomenon as a form of ellipsis rather than implicature.

Okazaki's (1994) study went beyond intuitive data in drawing from an analysis of conversational data between Japanese couples to argue that one of the primary functions of ellipsis is the expression of rapport and involvement. It was also apparently more clearly motivated in its application of the notion of ellipsis to the study of utterance-final conjunctive particles, as she argues in subsequent work that they are sometimes understood by interactants as "incomplete," in the sense that what the speaker thinks is easily inferred and thus can be deleted, may be to the listener a frustrating lack of verbalisation (Yoneha Okazaki 2003: 89). Such a perception often gives rise to diverging understandings of what is being communicated as evident in the

2 The intensification of particular speech acts such as thanks or apologies to give rise to politeness, as well as the avoidance of the marking of particular honorific or non-honorific forms, was found by Okamoto (1985) to be achieved primarily through verbal ellipsis. 
next example where a couple are discussing their different interpretings of a previous conversation in which Yumie ended one of her utterances with kara ('so').

(2) (Yumie and Tetsuo, who are married, are discussing their previous conversation about Yumie's trouble at the dry cleaning shop)

1 Y: Dakara, atashi iraira-shi-te-iru-n-da kara tte,

therefore I irritated-be-Prog-Nomi-Cop so Quot

2 ra-no ato wa, dakara mō anata ni yat-te-hoshi-katta noni

'ra'-Gen afterwards Top therefore now you by do-Te-want-Past though

3

anata wa yat-te-kure-na-katta tte iu no o.

you Top do-Te-give-Neg-Past Quot say Nomi Acc

(Therefore, [when] I said I was irritated, after the "so" what I wanted to say was I want you to do [the negotiation] but you didn't)

$4 \quad \mathrm{~T}: \quad$ [laugh] Sō i-eba yo-katta janai.

that way say-if good-Past Tag

5

Sō-iu füni i-wanai to watashi ni rikai, wakara-na-katta.

that way like say-Neg if I by comprehend understand-Neg-Past

(You should have said so, shouldn't you? If you don't say so, I can't comprehend, understand [your meaning])

(adapted from Yoneha Okazaki 2003: 92-93)

Yumie explains in lines 2-3 that what she had meant by the previous utterance she quotes in line 1 was she had wanted Tetsuo to help with the negotiations at the dry cleaning shop (Atashi iraira-shiteiru-n-da kara, 'I was very irritated so'). However, Tetsuo goes on to accuse Yumie in lines 4-5 of being unclear, and so he could not understand what she wanted. In other words, it becomes apparent in this conversation that Yumie and Tetsuo had different understandings of the meaning(s) arising from the utterance-final conjunctive particle kara in their previous conversation. Yet, while Yoneha (2003) frames her explication of this example of the diverging understandings of the meaning(s) that arose from the utterance-final conjunctive particle kara as involving different beliefs about the use of ellipsis (that is, omitting information), one could alternatively frame this as a dispute about what was implied by Yumie. It is apparent that although Yumie projected an implicature requesting Tetsuo's help at the dry-cleaners, Tetsuo did not make this inference, and thus this implicature was not interactionally achieved, at least not in the preceding conversation. An explication in terms of implicature thus complements work from the perspective of ellipsis, in that it allows the analyst to discuss the meaning(s) that are interactionally achieved (or not), as well as taking into consideration the interpersonal and interactional effects arising from whether these meanings are 'said' or 'implied.'

\subsection{The sentence-final particle approach}

The sentence-final or pragmatic particle approach to utterance-final conjunctive particles focuses primarily on how they are used to show relationships between utterances across turns (Iguchi 1998; Mori 1999; Tanaka 1999), the ways in which they give rise to various pragmatic effects (Fujita 2001; Itani 1992; Kamio 1994: 80; Nakayama and Ichihashi-Nakayama 1997: 612-613; Mori 1999; Ohori 1995: 208-211; 
Tanaka 1999; Xu 2002; Yamaguchi 2007: 189-190), as well as their role in turn-taking in conversation (Ohori 1995: 203; Mori 1999; Tanaka 1999). It is worth noting, however, that this approach overlaps to some extent with the ellipsis approach, since it also deals with inferences about a "missing" main clause (Mori 1999: 43), and thus the two approaches are not necessarily mutually exclusive (see for example, Maynard 1989; Tanaka 2004). The focus of such studies, however, is on how utterance-final conjunctive particles are exploited to give rise to pragmatic effects and offer turns through the sequential development of interaction.

Mori's (1999: 200-201) careful study of agreement and disagreement in Japanese conversation, for example, concludes that utterance-final kara is interpreted by recipients as implying weak or partial agreement and by speakers to imply disagreement, while speakers and recipients use kedo to mitigate a disagreement by implying partial agreement. While utterance-final conjunctive particles have been found to be used to hedge assertions in Japanese conversation, in particular, agreement and disagreement (Fujita 2001: 137-142; Itani 1992; Kamio 1994: 80; Mori 1999; Nakayama and Ichihashi-Nakayama 1997: 612-613; Ohori 1995: 208-211; Tanaka 1999; Yamaguchi 2007: 189-190), they also are exploited by speakers to offer interactional options to addressees as they can also act as turn-yielding signals (Maynard 1989; Mori 1999; Tanaka 1999, Tanaka 2004).

In the following example, taken from a telephone call where the caller is requesting information from an import company based in Kansai, the way in which utterance-final conjunctive particles can both mitigate speech acts as well as signal turns is apparent. ${ }^{3}$

(3) (The caller, 'C", has just gone through the automated answering system and is now speaking to one of the company's representatives, ' $\mathrm{R}$ ')

\begin{tabular}{|c|c|c|}
\hline & C: & $\begin{array}{l}\text { Ano:, o-torihiki hokokusho tte arimasu yo ne } \downarrow \\
\text { um Hon-transaction report form Quot exist-Pol FP Tag } \\
\text { (Um, there's the thing called a transaction report form, right?) }\end{array}$ \\
\hline & $\mathrm{R}:$ & $\begin{array}{l}\text { Hai. } \\
\text { (yes) }\end{array}$ \\
\hline & $\mathrm{C}:$ & $\begin{array}{l}\text { Sono ken de o-ukagai-shi-tai-n-desu keredomo.= } \\
\text { that matter with Hon-ask-do-want-Nomi-Cop(Pol) but } \\
\text { (It's that I'd like to ask about that matter but.) }\end{array}$ \\
\hline & R: & $\begin{array}{l}=\text { Hai. } \text { O-uke-itashi-masu node. } \\
\text { okay Hon-undertake-do(Hon)-Pol so } \\
\text { (Okay. It's that I'll handle it so.) }\end{array}$ \\
\hline & $\mathrm{C}:$ & $\begin{array}{l}\text { Hai. E:to jūichi-gatsu nijūyokka-zuke de } \\
\text { okay uh:m November 24th-dated with }\end{array}$ \\
\hline & & $\begin{array}{l}\text { ki-te-ru bun na-n-desu keredoMO: } \\
\text { come-Te-Prog portion Cop-Nomi-Cop(Pol) but } \\
\text { (Okay, um, it's that it concerns the one that's arrived which is dated } \\
\left.\text { November } 24^{\text {th }} \text { but, }\right)\end{array}$ \\
\hline & R: & $\begin{array}{l}\text { Hai. } \\
(\mathrm{Mhm})\end{array}$ \\
\hline & $\mathrm{C}$ : & [continues] (adapted from Yotsukura 2003: 302-303) \\
\hline
\end{tabular}

${ }^{3}$ See Appendix B for a list of transcription symbols used in the following examples. 
The caller's request in lines 1 and 3 for information about a particular transaction that was made concludes with an utterance-final keredomo (a variant form of kedo, 'but'), which not only mitigates this request, making it sound more tentative and thus less demanding, but also is taken up by the other participant as a turn-yielding signal in line 4. The company representative's offer to handle the issue in this line is followed by another conjunctive-particle node ('so'), which returns the speaking turn back to the caller, as well as implying a request for further details about the transaction the caller referred to in line 1, or at least allowing interactional space for this further information to be provided. In lines 5-6, the caller begins providing further information, and here the utterance-final keredomo mitigates the force of the assertion being made, as well as signalling its position as a subsequent topic in the caller's continuing narrative.

The various pragmatic effects associated with utterance-final conjunctive particles, which include blaming or expressing regret (noni), expressing reservation or hedging (kedo/ga), and appealing for the addressee's concern (kara/node), are contextually inferable or conventionalised according to Ohori (1995: 213). Iguchi (1998) goes on to argue that in the case of kara, while these pragmatic effects may involve implicatures, in situations where the implicatures are fairly indeterminate, kara can be characterised as a sentence-final particle since it "can be regarded as expressing the speaker's attitude toward the addressee or the situation stated in the utterances" (p.119).

The focus of the sentence-final or pragmatic particle approach to utterance-final conjunctive particles is thus somewhat different to that of the ellipsis approach in that it focuses almost entirely on its mitigating functions, with little said about the interpersonal effects (such as 'politeness' effects) of such mitigation. ${ }^{4}$ It also concentrates on explicating how these conjunctive particles are exploited in turn-taking across interactional sequences, and while these studies make passing reference to the inferences drawn from the strategic usage of these particles, little is said about the content of such inferences, namely, what implicatures arise through such interactions. ${ }^{5}$ In the following section, then, it is suggested that the notion of implicature may be fruitfully applied to the analysis of utterance-final conjunctive particles to complement these approaches, as it focuses both on how these particles can lead to the interactional achievement of implicatures by participants, as well as how they may trigger inferences giving rise to various interpersonal and interactional effects in conversation.

\section{Utterance-final conjunctive particles and implicatures}

The notion of implicature has been mentioned only in passing in most studies of utterance-final conjunctive particles in Japanese to date, in spite of the numerous references to inferences and implying in previous studies. It is only in more recent work

\footnotetext{
${ }^{4}$ However, as seen later from example (6) in section 3, mitigation and politeness should not be conflated, since mitigation (which decreases the illocutionary strength of utterances and/or discourse) does not always give rise to politeness (for further discussion see Caffi 1999, 2007; Holmes 1984; Sbisà 2001).

5 Although Iguchi (1998: 113-114) and Xu (2002: 70-71) address this in passing, they do not detail how these inferences arise, and so there remains space for a productive implicature-based account of these phenomena.
} 
that the concept of implicature has been foregrounded in the analysis of utterance-final conjunctive particles (Fukushima 2005: 83-86; Iguchi 1998: 113-114; Obana 2000: 295$301)$. In this section, building upon these previous studies, an approach to utterancefinal conjunctive particles that is grounded in the notion of implicature is proposed. In outlining this approach, the way in which implicatures arise from joint, collaborative interaction between conversational participants is first discussed, drawing primarily from Arundale's $(1999,2006)$ Conjoint Co-Constituting Model of Communication. The ways in which these implicatures may also give rise to various interpersonal and interactional effects are then considered. The notion of "(im)politeness implicature," which refers to instances where by virtue of implying something '(im)politeness' arises is introduced in the first part of this analysis. The notion of "interactional implicature," a term first coined by Mastumoto (1989: 210), which is used here to refer instances where by virtue of implying something interactional options are opened up to the participants, is also developed in the course of this analysis. ${ }^{6}$ The examples considered are drawn from a corpus of 508 tokens found in recordings of conversational and workplace data (98 tokens), film and television broadcasts (104 tokens), the researcher's own ethnographic field notes (24 tokens), as well as an initial pilot corpus gathered through discourse completion tests (279 tokens). All the examples in the corpus are thus gathered from data sources where the participants were not aware of the specific focus on (im)politeness and implicature in this paper. The conversational and workplace data are sourced from a corpus of 60 two to five minute requests made on the telephone (Xie 2000), transcripts of seven telephone calls made to a book company and importing company (Yotsukura 2003), and more than 30 excerpts from other transcripts of face-toface conversations between acquaintances (Ikuta 1988; Uchito 1997; Tanaka 1999). The film and television broadcasts include examples drawn from scripted dramas and semiscripted television talk shows (Aoki and Okamoto 1988; Iguchi 1998; Tanaka 2004), while the field notes include conversations noted down by the researcher in the Tokyo area from April 1998 to July 2000. Two discourse completion tests involving a total of 21 situations were also administered to 225 students at Tokyo University of Foreign Studies in January to June 2000. It is important to note, however, that while the tokens of utterance-final conjunctive particles arising in the discourse completion tests were used to initially characterise a range of potential implicatures associated with utterancefinal conjunctive particles, the tokens utilised in the present analysis are drawn only from the conversational and workplace data, as well as the film and television broadcasts. The obvious limitations of the data arising from discourse completion tests mean these examples were not amenable to an analysis of implicatures as an interactional achievement, as argued in further detail in the following section.

\subsection{The conjoint co-constitution of implicature in conversation}

The notion of implicature is attributed to Grice $(1967,1989)$ who introduced the concept as part of his broader programme on speaker meaning. However, since Grice did not offer a clear definition of implicature as such (Gauker 2001: 165; Saul 2002: 239), delimiting the scope of implicature remains a contentious issue in the field of

\footnotetext{
${ }^{6}$ Matsumoto (1989) defines interactional implicature as an "an unexpected choice [that] will invite interactional awkwardness and invoke inferences" (p.210), and so her notion is more akin to what is termed an "impoliteness implicature" in this paper.
} 
pragmatics. For the purposes of this analysis, then, implicature will be broadly defined as something implied in addition to what is literally said, or in terms of the metalanguage first proposed in Haugh (2002) and Haugh and Hinze (2003), "A says U and because of this B thinks something else in addition to $U$ that A did not say.",

Yet while Grice's work laid the foundation for much of the following analysis, it is suggested here that implicatures are not simply indirect meanings that hearers recognize as 'intended' by speakers, a view that follows from the received view of Gricean pragmatics (Grice 1989; Horn 2004; Levinson 1983, 2000), and arguably to some extent Relevance Theory (Sperber and Wilson 1995) as well. Instead, drawing from the Conjoint Co-Constituting Model of Communication (Arundale 1999, 2004, 2005; Arundale and Good 2002), it is argued here that implicatures "arise from joint, collaborative interaction between speakers and hearers" (Haugh 2007a: 85). The process of conjoint co-constitution is defined as the manner in which "each participant's cognitive processes in interpreting and designing are responsive to prior, current, or potential contributions the other participants make to the stream of interaction" (Arundale 2005: 59). In applying this model to the analysis of implicature, it is necessary to re-conceptualise implicatures as emergent phenomena, which arise through the dynamic, interactive processes that underlie conversation. ${ }^{8}$ It also entails a focus on participant meanings, those which are demonstrably contingently relevant to the participants (Bilmes 1985: 319-322; Sanders 1999: 132), as opposed to those imposed by the analyst. In other words, the focus of the analysis is on "participants' analyses of one another's verbal conduct - on the interpretations, understandings, and analyses that participants themselves make, as displayed in the details of what they say" (Drew 1995: 70 , original emphasis) to establish that (1) an implicature has indeed been projected and inferred by the participants, and (2) this implicature is procedurally relevant to the flow of discourse.

In the following example, the manner in which participants influence each other in the conjoint co-constitution of implicatures is readily apparent, as the interpretings of what was projected by the previous interlocutor is evident from their uptake. The implicatures arising in this conversation can thus be seen as interactionally achieved by the two interactants. In this particular extract from the conversation, A starts by saying the new car he has just bought is cheaper than he thought it would be.

(4) (A, a man in his fifties, is talking to his younger brother-in-law (B))
$1 \quad$ A: $\quad$ Sō, yasu-katta-desu.
that way cheap-Past-Pol
(Yeah, it was cheap)
2 B: Shikashi, moderu-chenji.
but model-change
(But a new model)
3 A: Un, sugune, moderu-chenji shi-ta kedo ne. yeah soon AtF model-change do-Past but Tag (Yeah, [the company] soon brought out a new model but)
4 B: Nē,shō ga nai desu yo nē, mō

${ }^{7}$ Where ' $A$ ' refers to the speaker, ' $B$ ' refers to the hearer/addressee, and ' $U$ ' refers to the utterance in question.

${ }^{8}$ For a more detailed explication of the three key principles underlying the Conjoint CoConstituting Model of Communication see Haugh (2007a: 97-104). 


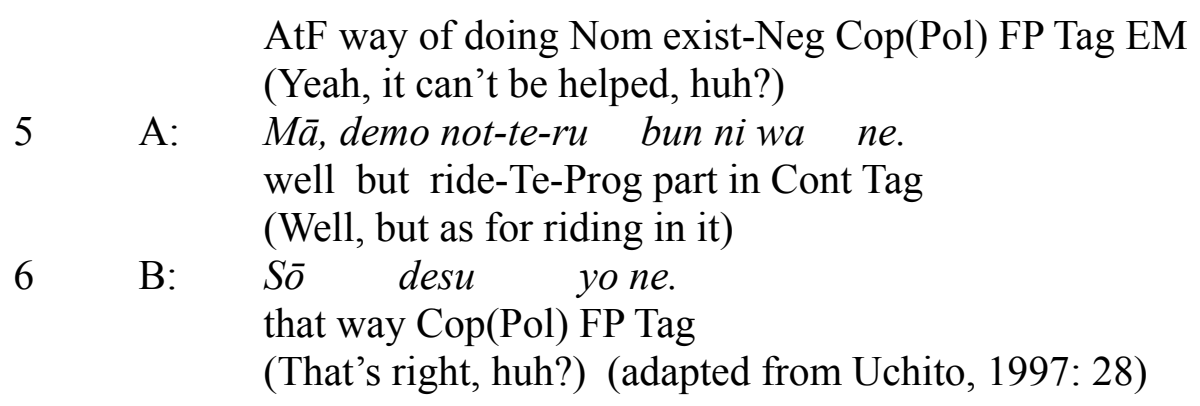

A first says that buying a new car is cheaper than he thought it would be in line 1 . B responds in line 2 by pointing out that the company brought out a new model soon after his brother-in-law bought the car, and this utterance is reiterated more fully by A in line 3. B apparently regards the new model being brought out as unfortunate, as evident in his comment in line 4 where he expresses sympathy for his brother-in-law's situation ( Nèe, shō ga nai desu yo nē, mō, 'Yeah, it can't be helped, huh?'), which presupposes that waiting to buy the newer model would have been better.

However, careful analysis of A's responses in lines 3 and 5 indicates that he holds a different viewpoint to that of his brother-in-law. The utterance-final kedo ('but') in line 3 is exploited by A to project an implicature, namely, it does not really matter to him that a new model came out (betsuni ii-n-desu), since the use of this conjunctive particle indicates that what he is implying contrasts in some way with the fact a new model was brought out soon after he bought the car. B's interpreting of A's utterance in line 3 , which is apparent from his response in line 4, shifts the focus away from this particular implicature to his viewpoint that it is unfortunate, and so does matter. A's subsequent response in line 5 expresses both his understanding of B's interpreting of his previous utterance in line 3 as A implying it was unfortunate, as well as echoing his previously projected implicature, namely, it does not really matter to him, since the appearance of a newer model does not affect his driving of his new car per se. B's response in line 6, where he expresses agreement, appears to concede to A's viewpoint of the situation, and thus indicates the implicature arising in line 3 (and echoed in line 5) has been conjointly co-constituted by the two interlocutors. While B arguably keeps his options open in this expression of agreement in line 6 , since it is not totally unambiguous as to whether he is expressing agreement with A's viewpoint or his own, this does not affect the supposition that A's implicature (that it does not matter A did not buy the latest model) emerges as a joint product in the course of this interaction, with the utterance-final conjunctive particle playing a crucial role in this process. In the following section, the assumption established in previous studies that one of the key interpersonal effects of the use of utterance-final conjunctive particles is '(im)politeness' is analysed in greater detail. It is suggested that these interpersonal effects arise through the conjoint co-constitution of '(im)politeness implicatures.'

\subsection{Utterance-final conjunctive particles and (im)politeness implicatures}

The notion of (im)politeness implicature, which builds upon earlier work in the field (Brown and Levinson 1987; Leech 1983), refers to instances whereby implying something in addition to what is literally said, the speaker shows what he/she thinks of the hearer and/or speaker (Haugh 2007a: 85-86). In the case of Japanese, 
'(im)politeness' (teinei, reigi) arises through what the speaker shows he or she thinks or the 'place' of others and him/herself through such implicatures (Haugh 2005, 2007b; cf. Ide 1989: 230; Lebra 1976: 67; Matsumoto 1988: 405). The notion of 'place' in Japanese encompasses both the place one belongs (uchi), namely "the interactional achievement of group-based relationships of belonging, and the obligations (gimu) and dependencies (amae) accompanying such belonging" (Haugh 2007b: 660) and the place one stands (tachiba), or "the interactional achievement of one's public persona or social standing as distinct from others, including one's position or role (ichi, yakuwari), status (mibun, chi'i) and current state or circumstances (jokyō)" (Haugh 2005: 47, Haugh 2007b: 660). The notion of place is used in place of Brown and Levinson's (1987) concepts of positive and negative face in this paper, since the various ways in which politeness may arise in Japanese, for instance in contexts where expressions such as yoroshiku onegaishimasu (lit. 'I make a request of you and hope things go well') are used, are arguably not adequately explicated using the latter concepts (Haugh 2005: 4344; Matsumoto 1988, 2003).

In order to establish that the analyst's interpreting of these evaluations as involving (im)politeness is consonant or analogous with the participant's understandings it is necessary, however, to go beyond the explicit or implicit understandings of participants evident through their responses in the sequential development of the conversation to a wider theoretical framework. In the following analysis it is suggested that the notion of 'place,' whilst not necessarily an understanding participants would themselves hold, is consonant with the participant's interpretings of the interpersonal implications of the implicatures that arise in these conversations. In this section, then, the various ways in which the utterance-final conjunctive particles kara/node ('so', 'because'), kedo/ga ('although', 'but'), and tara/ba/to ('when', 'if') are used by Japanese speakers to project (im)politeness implicatures are explored with reference to the notion of 'place.'

Kara/node: The conjunctive particles kara and node are attached to clauses to form subordinate clauses, and indicate a cause or reason for an action or attitude that is canonically described in the main clause. The fact that kara or node indicate that what precedes the conjunction is a reason for or cause of something can be exploited to give rise to (im)politeness implicatures. However, kara in the utterance-final position sounds slightly more imposing than node, since the former has connotations of the speaker trying to justify the reason for his or her response more than in the latter case (cf. Takeuchi 1997: 146). Utterance-final node thus tends to be associated with more formal speaking contexts, while utterance-final kara may appear in either formal or informal situations. ${ }^{9}$

In the following telephone conversation there are two examples of politeness implicature conjointly co-constituted through the use of utterance-final kara (which is used instead of node as this is a fairly informal context in which the students are chatting).

(5) (A and B are both university students. A has called up to ask about notes from a class she missed)

$1 \quad$ A: Kyō wa Russeru no jugyō de-mashi-ta?

${ }^{9}$ This was reflected in the researcher's corpus where 40 out of a total of 43 tokens $(93 \%)$ of utterance-final node were in business or other formal situations. Utterance-final kara, on the other hand, was found in both formal and informal situations. 
today Top Russell Gen class appear-Pol-Past

(Did you go to Russell's class today?)

2 B: Iya, de-te-nai.

no appear-Te-Neg

(No, I didn't go)

3 A: Ee, ja, senshü toka de-te-masu yo ne.

uhm then last week or appear-Te-Pol FP Tag

(Uhm, then, you did go last week and so on didn't you?)

$4 \quad$ B: $\quad A$, senshū de-te-ru.

oh last week appear-Te-Prog

(Oh, I was there last week)

5 A: Ja, senshū no nōto mise-te-morai-tai-n-de,

well last week Gen notes show-Te-receive-want-Nomi-Cop(Te)

6

kyō kari-te-kaet-temo ii-desu ka?

today borrow-Te-go home-if good-Pol Q

(Well, can you show me last week's notes and let me borrow them today?)

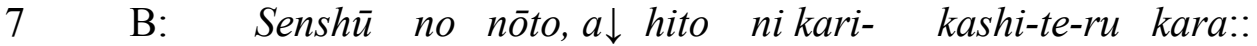

last week Gen notes oh person to borrow- lend-Te-Prog so

(Last week's notes, oh, I have borrow- lent them to someone so...)

$8 \quad$ A: $\quad$ A, sō na-n-desu ka.

oh that way Cop-Nomi-Cop(Pol) Q

(Oh, is that right?)

9 B: Tabun, ni, san nichi atode kaet-te-kuru kara::

probably 23 days after return-Te-come so

([They] will probably return them after two or three days so...)

$10 \mathrm{~A}: \quad J a, \quad$ tsugi watashi kari-temo ii-desu ka?

well then next I borrow-if good-Pol Q

(Well then, may I borrow them next?)

11 B: $\quad$ A, ii yo.

oh good FP

(Oh, that's fine) (Xie, 2000: BF03JOM58)

A first asks if B went to class that day (line 1), but upon finding he did not (line 2), she goes on to ask to borrow some notes from the previous week's class in lines 5-6. B responds by saying he has already lent the notes to someone else. The utterance-final kara in line 7 is exploited by B to imply that he is not able to give the notes to A today, and the uptake of this implicature by $\mathrm{A}$ is apparent from her response in line 8 . In his subsequent speaking turn in line 9, B implies that he can lend the notes to A after two or three days, with this implicature also being projected by the utterance-final kara. In line 7 , then, the utterance-final conjunctive particle is exploited by B to imply a refusal of A's initial request, while through the utterance-final kara in line 9 he implies an offer to give the notes to A later. The subordinate clauses to which the utterance-final conjunctive particle kara is attached are thus grounded as reasons for the implied refusal and offer respectively.

It is also arguable that both of these implicatures give rise to politeness as through them B is able to show concern for the place A belongs as a fellow student, whom $\mathrm{B}$ is expected (to a lesser or greater degree) to assist where possible. More 
specifically, politeness arises from the implicature arising in line 7 because $\mathrm{B}$ foregrounds the reason for not being able to comply with A's request in making it part of what is said, and also indicates his reluctance to make this refusal by leaving it unsaid, thereby showing concern for the place A and B belong as follow students. On the other hand, politeness arises from the implied offer in line 9 because B shows he is willing to accommodate to A by leaving options open in terms of his offer, as he does not make his offer explicit, and in doing so allows A more interactional space in which to take up the offer or not in order to show concern for the place A stands.

However, while implicatures triggered by utterance-final conjunctive particles may give rise to politeness, the co-constitution of politeness is not necessarily a foregone conclusion. In the next example, taken from the Japanese television drama Fuzuroi no Ringotachi ('Odd Apples'), Shuichi has called Yoshio and Harue for help after finding his girlfriend Natsue has cut her wrists in an attempted suicide.

(6) (Harue, who is a nursing student is examining the cuts on Natsue's wrists.)

\begin{tabular}{|c|c|c|}
\hline & Y: & $\begin{array}{l}\text { Byoin e ika-naku-te ii? } \\
\text { hospital to go-Neg-Te good } \\
\text { (Is it okay if she doesn't go to a hospital?) }\end{array}$ \\
\hline 2 & H: & $\begin{array}{l}\text { Daijōbu. Kusuriyasan, kinjo ni ari-masu? } \\
\text { okay pharmacy neigbourhood in have-Pol } \\
\text { (Yes. Is there a pharmacy in the neighbourhood?) }\end{array}$ \\
\hline 3 & S: & $\begin{array}{l}\text { Aru kedo, shimeru no hayai kara:: } \\
\text { have but close Nomi early so } \\
\text { (There is, but they close early so...) }\end{array}$ \\
\hline 4 & Y: & $\begin{array}{l}\text { Sonna no, ake-te-morau yo. Nani kat-te-ki-tara ii? } \\
\text { that Nomi open-Te-receive EM what buy-Te-come-if good } \\
\text { (I'll ask them to open [the store]. What shall I buy?) }\end{array}$ \\
\hline 5 & H: & $\begin{array}{l}\text { Kaku mono, aru kashira? } \\
\text { write thing have wonder } \\
\text { (Do you have something to write with?) } \\
\text { (adapted from Iguchi 1998: 113) }\end{array}$ \\
\hline
\end{tabular}

In this extract from the interaction, Yoshio first asks in line 1 whether Natsue will need to see a doctor, to which Harue responds that she just needs something from the pharmacy. Shuichi responds to Harue's inquiry in line 2 as to whether there is a pharmacy open nearby by saying while there is one, they close early. The utterance-final kara here triggers the inference that the pharmacy will not be open. The fact that Shuichi leaves his assumption that the local pharmacy will be closed unsaid gives rise to the impression that he is distancing himself from taking responsibility for the situation with his girlfriend Natsue, because it seems as if he believes the situation (that is, of the local pharmacy being closed) is unavoidable and so nothing can be done about it. It is this avoidance of responsibility to which Yoshio responds somewhat angrily in line 4, when he argues that they can ask the pharmacy to open up since it is an emergency. Yoshio then goes on to ask what he should buy, thereby disputing Shuichi's unsaid assumption that they will not be able to get anything from a pharmacy for Natsue. In this situation, then, it is apparent that the utterance-final conjunctive particle kara in line 3 , whilst triggering the co-constitution of an implicature, does not give rise to politeness as one might expect. Instead, it is interpreted by Yoshio as a lack of concern on 
Shuichi's part, as evident from his anger at Shuichi's avoidance of responsibility.

Kedo/ga: The disjunctive coordinate conjunctions kedo and ga ('although', 'but') are both used to combine clauses that express opposing or contrasting ideas, in a similar manner to the English conjunction but, although as argued by Fukushima (2005), $g a$ has a number of other non-conflictive/contrastive functions (referential $g a$, insertive $g a$, and continuative $g a$ ). The fact that kedo or $g a$ can be used to coordinate (semantically) opposing clauses can be exploited to facilitate the conjoint coconstitution of (im)politeness implicatures. In the next example, Jun implies that he is not interested in going along to see the soccer match to which he has been invited by Yusuke.

(7) (Yusuke and Jun, who are friends, are talking about soccer)

1 Y : Zerokussu Suupaa Kappu o mi-ni ika-nai?

Xerox Super Cup Acc watch-to go-Neg

(Do you want to go and see the Xerox Super Cup?)

2 J: Dono chiimu?

which team

(Which teams [are playing]?)

3 Y: Jubiro tai guranpasu

(Jubiro versus Guranpasu)

$4 \quad$ J: Zen Nippon dat-tara tobitsuku-n-da kedo ne::

all Japan Cop-if jump at-Nomi-Cop but Tag

(If it were a national league game, I might be grabbed but...)

$5 \quad \mathrm{Y}: \quad A, s \bar{o} \quad k a$.

oh that way $\mathrm{Q}$

(Oh really?) (Tokyo, February 2000)

In response to Yusuke's invitation in line 1 to go to watch a soccer match, Jun asks which teams are playing before going on to imply in line 4 that he is not interested, thereby refusing Yusuke's invitation. The utterance-final kedo is critical to the coconstitution of this implicature, since the relationship of contrast indicated by this conjunctive particle facilitates the inference underlying the implicature. In this example, a contrast arises between what is said (Zen nihon dattara tobitsuku $n d a$, "If it were a national league game, I might be grabbed'), and what is implied, which is something to the effect of 'I am not interested in going to see this match (since it is not a national league one).' Politeness is associated with this implicature because Jun shows concern for the place Yusuke belongs as one of his friends. More specifically, by implying this refusal and making his reason for doing so explicit, Jun leaves room to accommodate to what Yusuke thinks about the game, making it easier for Yusuke to make future invitations, thereby showing appropriate concern towards their friendship. The interactional options offered also decrease the illocutionary strength of the refusal by making the refusal sound more tentative and thus less abrupt.

Politeness implicatures may also arise in situations where utterance-final kedo is used to indicate the speaker's uncertainty, as seen in the next example. In this extract taken from a Japanese television talk show, the guest is commenting on the alternative name for zucchini in English.

(8) (A guest, who is an academic, is explaining to the host about a particular recipe) 
1 Guest: Ee kore wa karifurawā to zukkini desu ne. uhm this Top cauliflower and zucchini Cop(Pol) Tag Kurojetto to eigo dewa mōshi-masu kedo. courgette Quot English in Cont call(Hon)-Pol but (This is [with] cauliflower and zucchini. In English it is called courgette but)

3 Host: Zukkini tte ano (0.2) chotto kyūri mitaino. zucchini Quot uhm (0.2) a little cucumber like (Zucchini is like a cucumber)

(Yes, yes)

In this example, the guest's assertion that while 'zucchini' is generally only known as zukkini in Japanese, in English it is also called a courgette concludes with an utterancefinal kedo in line 2. The uncertainty implied by opening up the possibility of the guest not being correct in this assertion, allows him "to sound less assertive or pretentious as he refers to the term in English" (Tanaka 2004: 91), in order to show he does not think too highly of the place he stands. Politeness thus arises since he is expressing modesty about his knowledge of such things. The academic may, of course, be in reality quite certain about what he is asserting, but the utterance-final conjunctive particle allows him to imply a certain degree of uncertainty in order to give rise to this politeness effect.

While speakers may exploit utterance-final kedo or ga to imply a negative response (such as in example 7) or uncertainty (as in example 8), they can also facilitate inferences that the speaker is offering interactional options to the addressee. In the following example, the participants have been talking about the possibility that $\mathrm{K}$ will go to visit a mutual acquaintance.

(9) ( $\mathrm{Y}$ and $\mathrm{K}$ are talking on the phone about $\mathrm{K}$ visiting a mutual acquaintance)

$1 \quad \mathrm{Y}: \quad \begin{aligned} & (\text { De }) \text { mata }= \\ & \text { (and again) }\end{aligned}$

$2 \mathrm{~K}: \quad=n=$

$$
\text { (Yeah) }
$$

$3 \mathrm{Y}: \quad=$ ne: $i t-t a$ toki $[$ ni a-eru to ii-n-da kedo ne.=

Atf go-Past when [to meet-Pot Quot good-Nomi-Cop but Tag

(Although it would be good if [we] could meet when [you] go there but)

$4 \quad \mathrm{~K}:$

$[S \bar{o}$

(Right)

$5 \quad=S \bar{o} \quad d a \quad n e: .=$

that way Cop Tag

(It would be wouldn’t it?) (Tanaka 1999: 198-199)

In this extract, $\mathrm{Y}$ suggests in line 3 that they meet together if $\mathrm{K}$ really decides to visit their mutual acquaintance. The utterance-final kedo in this instance leaves options open to $\mathrm{K}$ as to how she might respond. In other words, an implicature something like 'I don't know if that would be okay with you' is projected by Y in line 3, with K's uptake of this implicature being apparent in line 5 from her expression of agreement with the 
suggestion (although she has already anticipated it would appear from her overlapping expression of agreement in line 4). The conjoint co-constitution of this implicature also gives rise to politeness, as by offering the decision to $\mathrm{K}$ as to whether $\mathrm{Y}$ should go along to visit at the same time as $\mathrm{K}, \mathrm{Y}$ leaves options open to $\mathrm{K}$ as to how she might respond, thereby showing respect to the place K stands.

Tara, $b a$, to: The conjunctive particles tara ('when/if'), $b a$ ('if'), and to ('when') are also attached to clauses to form subordinate clauses. They are used to indicate that the fulfillment of the action or state in the main clause following them is conditional upon the action or state expressed in the subordinate clause being realised. These conjunctive particles can thus be exploited in the conjoint co-constitution of (im)politeness implicatures, since the inferences underlying the co-constitution of the implied "main" clause must establish a conditional relationship between what is said and the implicature.

The way in which a conditional utterance-final conjunctive particle can trigger the co-constitution of a politeness implicature is apparent in the next example, taken from a "Tora-san" film. In the following extract, Sakura's Section Head is talking with Sakura about what Kamakura, a prospective marriage partner whom she was introduced to by the Section Head, thought of their recent omiai ('arranged meeting').

(10) (The section head is talking with Sakura in the office)

1 Section Head: Jitsuwa, ima made Kamakura-san ga mie-te ne, anta ni actually now until Kamakura-Pol Nom visit-Te Tag you to a-e-nai ga, kureguremo yoroshiku to... Sorede ne, meet-Pot-Neg but best regards Quot with that AtF tsumari...ketsuron kara yuu to:: in short conclusion from say if (Well, Mr Kamakura was just here now. [He said] he couldn't meet you, but he wanted me to convey his best regards to you...And, well...if I say from what the gist of it is...)

$4 \quad$ Sakura:

Wakat-te-masu. O-kotowari ni mie-ta-n-desu ne. understand-Te-Pol Hon-refusal to visit-Past-Nomi-Pol(Cop) Tag (I understand. He came to tell you that he's turning the offer down)

5 Section Head: Un...kimi ni wa sumanai ga yeah you to Top feel sorry but (Yeah...I feel sorry for you but...) good-Nomi-Cop(Pol) natural Cop(Pol) so (That's okay. It's only natural so...)

Section Head: Sō...waru-katta na.

that way bad-Past EM

(Well...I'm sorry)

(adapted from Aoki and Okamoto 1988: 76-77)

The Section Head starts by relating what Kamakura said about their arranged meeting in lines 1-2, but his utterance trails off with the conditional to conjunctive particle in line 3 , through which he projects an implicature, namely that Kamakura was not interested in Sakura. The co-constitution of this implicature is apparent from Sakura's response in 
line 4 where she says she understands (what has been implied), and then goes on to verbalise what the Section Head had only implied. The Section Head's subsequent expression of empathy in line 5 , is followed by Sakura trying to downplay any negative feelings she might have in line $6,{ }^{10}$ to which her boss responds by apologising. Politeness also arises from this implicature, because the Section Head shows through this implicature and the trailing-off utterance-final conjunctive particle that he is reluctant to give this bad news to Sakura and hurt her feelings, and thus shows concern towards the place she stands. In other words, the use of an utterance-final conjunctive particle here indicates the speaker's reluctance to perform a particular speech act as well as expressing the speaker's hesitance in projecting the implicature, thereby giving rise to politeness.

An implicature triggered by an utterance-final conditional particle can also give rise to impoliteness effects in some situations. In the next example, an utterance-final $b a$ triggers an inference that the speaker does not particularly care about what the other interactant has just said.

(11) (Two students are chatting)

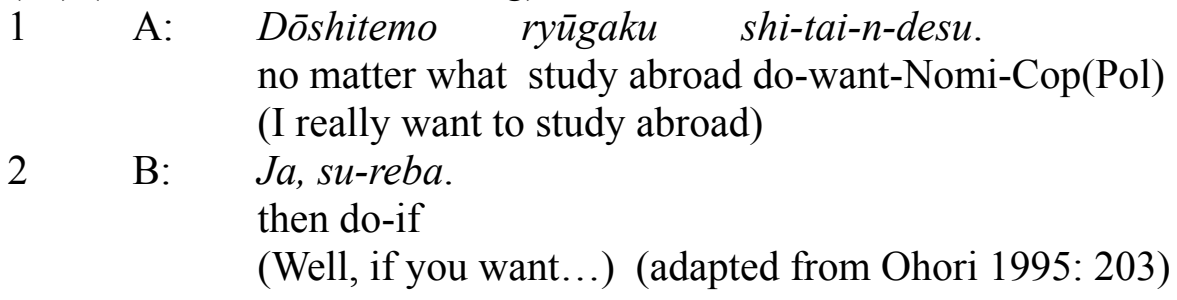

In this short exchange, B responds to A's expressed desire to go on a study abroad programme with a fairly minimal response, which leaves unsaid something like ii- $n$ janai? ('why not?'). Since the verb-ba ii-n-janai form is used fairly conventionally to make a suggestion or to express permission for the other person's activity the unsaid element is probably better characterised as elliptical. However, in leaving this unsaid, B also implies a certain degree of indifference to A's desire to go overseas. The implicature of indifference shows B is not concerned for the place they belong as fellow students, and thus potentially gives rise to impoliteness.

From the examples analysed in this section, it is apparent that by implying something instead of simply saying it, (im)politeness implicatures may be conjointly coconstituted. These politeness effects may arise in various ways, including foregrounding the reasons for what has been implied, accommodating to the addressee, mitigating the illocutionary strength of the speech act in question by making it sound more uncertain or less abrupt, or by expressing the speaker's reluctance to say something. Impoliteness effects, on the other hand, may arise from exploiting implicatures to express indifference towards other participants. The implicatures which are triggered by utterance-final conjunctive particles do not always give rise to (im)politeness, however, as other interpersonal effects arising from such implicatures include the avoidance of personal responsibility. In the following section, we will see how these kinds of implicatures can also give rise to various interactional effects.

\footnotetext{
${ }^{10}$ The utterance-final kara in line 6 is an example of the post-position of a subordinate clause (i.e., Atarimae desu kara, ii $n$ desu, 'It's only natural so that's okay'), and thus does not involve the coconstitution of an implicature. While the focus in this paper is on how utterance-final conjunctive particles can give rise to implicatures, this is not to say that they always trigger implicatures.
} 


\subsection{Utterance-final conjunctive particles and interactional implicatures}

While utterance-final conjunctive particles may give rise to interpersonal effects through the conjoint co-constitution of (im)politeness implicatures, they may also have interactional effects in the overall flow of the conversation. The notion of "interactional implicature," first coined by Matsumoto (1989: 210), is used here to refer to instances where by virtue of implying something in addition to what is literally said, interactional options are opened up to the participants. The content of the inferences underlying interactional implicatures range from those which are fully determinate through to less determinate ones. Interactional implicatures thus involve, at times, participants inferring a range of what Sperber and Wilson (1995: 195-197) term "weak implicatures,", as suggested in the following analysis.

In the following example, the way in which a variety of utterance-final conjunctive particles can be exploited by participants in the conjoint co-constitution of interactional implicatures is illustrated. In this conversation, one of the students is asking to borrow some notes from a previous class she missed.

(12) (A and B are both students who have just met in the corridor at the university)

$1 \quad$ A: $\quad$ A, senpai sumimasen, anō, sensh $\bar{u} \quad$ no jugyō chotto

oh senior excuse me uhm last week Gen class a little

2

de-na-katta-n-desu keredomo, anō, nōto

go-Neg-Past-Nomi-Cop(Pol) but uhm notes

$3 \quad k a s h i-t e-i t a d a-k e-n a i-n$-deshō ka?

lend-Te-receive(Hon)-Pot-Neg-Nomi-probably Q

(Oh, senpai [lit. 'my senior'], uhm, I didn't go to last week's class. But, uhm, could [you] lend [me your] notes?)

4 B: Un, betsuni ii kedo.

yeah particularly good but

(Yeah, that's fine [with me] but)

$5 \quad$ A: $\quad$ E, hontō desu $\quad$ ka. E, ano, ima sugu, soreto:::

oh really Cop(Pol) Q oh uhm now soon or:::

(Oh really? Oh, [shall I borrow it] now or...?)

6 B: Un, ima mot-te-ru kara, kashi-te-ageru yo. yeah now have-Te-Prog so lend-Te-give EM

(Yeah, I have them[with me] now, so I can lend them to you)

7 A: Aa, honto, tasukari-masu. Itsu kaese-baii-n-desu ka.

oh really help-Pol when return-if good-Nomi-Cop(Pol) Q

(Oh, [that] really helps [me] out. When shall I return [the notes]?)

8 B: Ano, raishū no jugyō mae da kara,

um next week Gen class before Cop so

9 raishū no getsuyōbi ni mot-te-ki-te.

next week Gen Monday on bring-Te-come-Te

(Um, before next week's class, so [please] bring them next week on

11 The notion of "weak implicature" builds upon Grice's (1989: 39-40) initial observation than many implicatures are in fact indeterminate in regards to their content. 


\begin{tabular}{|c|c|}
\hline & Monday) \\
\hline A: & $\begin{array}{l}\text { A, dōmo arigatō gozaimasu. } \\
\text { oh very much thank-Hon-Pol }\end{array}$ \\
\hline 11 & $\begin{array}{l}\text { Kondo shi-masu kara::: } \\
\text { next time Hon-sign of gratitude do-Pol so } \\
\text { (Oh, thank you very much. Next time I will show my appreciation so...) }\end{array}$ \\
\hline B: & $\begin{array}{l}\text { Un, ore mo ika-na-kya ikenai kara::: } \\
\text { yeah I also go-Neg-if no good so } \\
\text { (Yeah, I have to head off so...) }\end{array}$ \\
\hline A: & $\begin{array}{l}\text { A, domo arigatō gozaimasu. } \\
\text { oh very much thank-Hon-Pol } \\
\text { (Oh, thank you very much) (Xie 2000: JBF18JOM52) }\end{array}$ \\
\hline
\end{tabular}

Student A opens the conversation by asking to borrow some notes from a class she missed (lines 1-3). Student B responds to this request by agreeing in line 4 to lend his notes, however, his utterance ends with the conjunctive particle kedo ('but'), which not only signals that $\mathrm{B}$ is offering the speaking turn back to $\mathrm{A}$, but also gives rise to a range of interactional implicatures. These implicatures, although not fully determinate, allow B to shift the focus from whether it is okay for A to borrow the notes to the actual details of lending those notes by opening up interactional options for A. More specifically, through these implicatures B is not only leaving it open as to whether A really borrows those notes (something like 'are you sure you want them, since they may not be any good?'), he is also opening up the flow of the discussion in regards to when and where he might pass the notes to A. Student A then accepts B's offer and goes on to ask when she might take B's notes in line 5. The utterance-final conjunction soreto ('or') also opens up interactional options by leaving open the possibility that she might borrow the notes later if it is not convenient for B to pass his notes to her now.

After agreeing to immediately pass the notes to A, they go on to discuss when she should return the notes to B (lines 6-9). The conversation then moves into the closing phases when A thanks B for the notes (line 10), and then offers to do something in return to show her appreciation (line 11). The appearance of an utterance-final kara ('so') here triggers the co-constitution of a range of interactional implicatures, as well as indicating that $\mathrm{B}$ is offering the speaking turn back to $\mathrm{A}$. These fairly indeterminate interactional implicatures leave it open as to what the orei ('sign of gratitude') might be, but at the same time emphasize that B appreciates A lending her the notes (something like '[so] please don't think I don't really appreciate this', 'I won't forget this' and so on), as well as initiating the closing sequence of the interaction. B in turn responds in line 12 by acknowledging A's thanks (un, 'yeah'), as well as displaying an understanding that the conversation is indeed coming to a close. An utterance-final kara is also in evidence here, and once again facilitates the co-constitution of a range of interactional implicatures centred on leave-taking (something like, 'I guess we have to finish up here', 'I don't to want to offend you by rushing off but [I have to head off]' and so on). A then displays understanding of these interactional implicatures by responding in turn with thanks (line 13), thereby signaling her acceptance of the closing of the conversation.

As was noted in the previous section, while the denotational meanings of kara and node are essentially the same ('because', 'so'), their connotations are somewhat different. Kara tend to be associated with expressing the speaker's will or conjecture, 
while node is often employed in describing a reason or cause that is objective, or at least beyond the control of the speaker to alter. For this reason node is more often used in situations requiring a greater degree of formality, as seen in the next example, where a customer has called on the phone to report they have received an incomplete shipment from Tokyo Books.

(13) (The customer, ' $C$ ', has finished explaining which books were missing from the shipment to the book company representative, ' $R$ ')

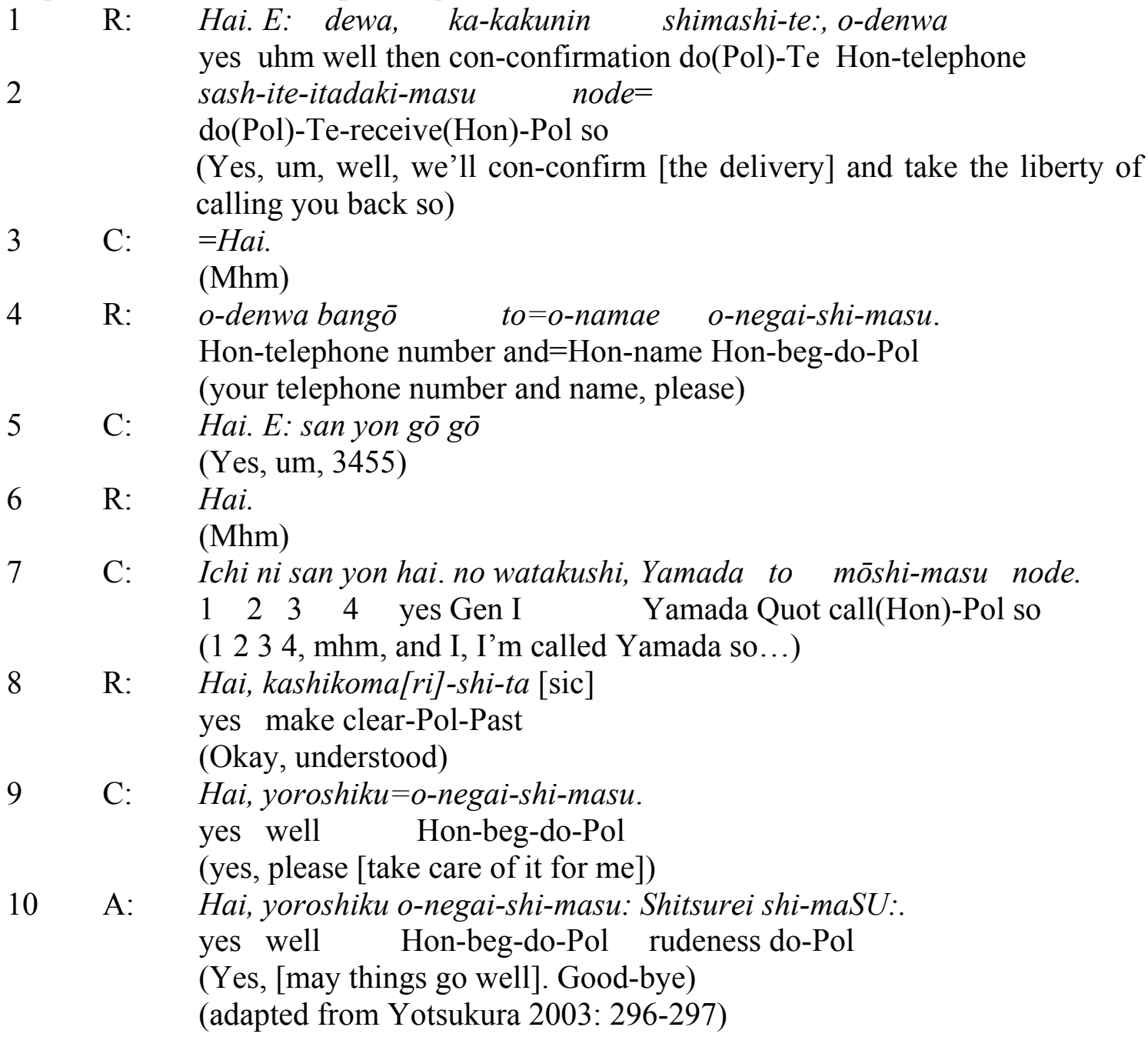

In the above excerpt, which is taken from a longer telephone conversation between a customer and the representative of a book company in Tokyo, the book company representative offers to investigate the missing part of the order, and so asks for the customer's name and contact details (lines 1-4). The customer responds in turn by offering those details (lines 5-7). In line 7, however, an utterance-final conjunctive particle node is used by the customer to trigger a range of interactional implicatures as well as easing the transition of the speaking turn back to the company representative. The interactional implicatures projected in this instance centre on the customer once again implying his request that something be done about this matter, although options are left open to the customer representative as to how this might be accomplished. This implied request also signals the closing phase of the conversation, since it has become 
apparent in the course of the interaction that securing the company's action on this matter was the purpose of the customer's call. The customer representative's uptake of these implicatures is evident from her response in line 8 where she acknowledges this implied request, and also responds to this call for the closing of the conversation, with the customer then going on to make the implied request partially explicit in line 9 . The 'objective' connotations of node are evident in that it is utilised in utterance-final position for an utterance that gives details of the customer's name and telephone number, which is also consistent with the greater degree of situational formality in this extract compared to the previous example.

From the examples analysed in this section, it is apparent that by implying something instead of simply saying it, interactional implicatures may be conjointly coconstituted. These implicatures are often "weak" or somewhat indeterminate so as to leave a greater range of interactional options to the addressee, but despite this apparent indeterminancy, they contribute to the flow of the interaction, being involved in the facilitation of turn-taking, conversational closing and leave-taking, and reaffirmation of decisions that have been jointly reached through the course of the interaction.

\section{Implications}

Utterance-final conjunctive particles facilitate the conjoint co-constitution of implicatures, because they assist the recipient in making inferences that the preceding clause is (1) a reason or cause for, (2) in opposition or contrast to, or (3) a condition underlying something which has been left unsaid. These conjunctive particles are also exploited by Japanese speakers to give rise to a range of interpersonal and interactional effects in conversation. While these effects have been treated as instances of ellipsis, or as pragmatic particles that index particular interactional moves by scholars to date, in this paper it has been suggested that analysing these effects from the perspective of implicature theory offers another complementary perspective on this phenomenon. The notions of (im)politeness implicature and interactional implicature were developed in order to discuss how utterance-final conjunctive particles may trigger inferences leading to the conjoint co-constitution of politeness as well as offering interactional options to the participants. By carefully analysing the projection and uptake of these implicatures, which is apparent from the sequential development of interpretings co-constituted through these interactions, it was argued that the analysts' and participants' perspectives can be better reconciled to avoid the imposition of an analysis by the researcher which is not contingently relevant to those participants. This approach also enabled the researcher to more closely analyse how utterance-final conjunctive particles are exploited by Japanese speakers to give rise to such effects.

The results of this analysis also have implications for the development of a more comprehensive theory of implicature that is grounded in a careful analysis of participants' understandings. The first implication relates to the issue of the cancellability of implicatures. While it was argued that utterance-final conjunctive particles can be exploited by speakers to project implicatures, it was found that in acting as a trigger for these inferences, the speaker also retains greater control over the coconstitution of the concomitant implicatures. In particular, in the cases of kara/node and tara/ba/to it is difficult to (explicitly) cancel or (implicitly) suspend the inferences underlying the implicatures that are triggered. Thus, while "cancellability" is often 
proffered as a necessary (but not sufficient) test for implicatures (Bach 2006; BlomeTillmann 2008; Burton-Roberts 2006; Grice 1989: 44; Levinson 2000: 15; Sadock 1978), closer analysis of (im)politeness and interactional implicatures arising from these utterance-final conjunctive particles supports recent work in countering this assumption (Carston 2002: 138-139; Weiner 2006). It appears that in many cases the implicatures arising from utterance-final conjunctive particles are neither explicitly deniable nor implicitly suspendable through additional contextual information. A comprehensive theory of implicature must therefore more fully explore the extent to which explicit and contextual cancellability (Blome-Tillmann 2008) are useful diagnostics for identifying implicatures, by complementing neo-Gricean and Relevance theoretic analyses of implicature as an essentially linguistic phenomenon with recently emerging analyses of implicature as interactionally achieved through communication.

The second implication arising from this analysis involves the pragmatic processes underlying the derivation of such implicatures. Considerable attention has been paid in pragmatics to the classification of the meaning of conjunctive particles, for instance, as either conventional implicatures (Grice 1989; Potts 2005; cf. Bach 1999) or generalised conversational implicatures (Levinson 2000), or alternatively as procedural meanings that constrain the derivation of explicatures (and sometimes implicatures) (Blakemore 1987, 2002; Carston 2002, 2004; Iten 2005; Sperber and Wilson 1995). However, the examples of implicatures discussed in this paper, which have been shown to give rise to further interpersonal and interactional effects in some instances, suggest that we are potentially dealing with three layers of meaning in the case of utterancefinal conjunctive particles in Japanese conversation. The first layer of meaning involves the procedural meaning of the conjunctive particles, the second potential layer of meaning involves what may be implied through exploiting the sense that something has been "left unsaid" when such conjunctive particles are found in utterance-final position, and the third potential layer of meaning involves the interpersonal or interactional implications that may arise as a result of leaving something unsaid. For the sake of clarity, then, it is suggested that the term implicature be reserved for the second layer of meaning, as it is only at this layer of meaning that implying is demonstrably contingently relevant to participants. The Relevance Theoretic notion of procedural meaning can thereby be retained for the first layer of meaning (as recently argued by Matsui 2002 and Sasamoto 2008 in the case of Japanese connectives), and the term implication used to refer to the interpersonal and interactional meanings that can arise when utterance-final conjunctive particles appear. It is argued here that it is only by keeping these layers of meaning analytically distinct that we will be able to untangle the pragmatics processes underlying these various layers of meaning. While utterance-final conjunctive particles may at times facilitate the inferences underlying these implicatures, the question of whether default or nonce inferencing is involved in each instance is ultimately a matter for further empirical investigation.

In conclusion, then, the analysis proposed in this paper has indicated that the appearance of utterance-final conjunctive particles can lead to the conjoint coconstitution of (im)politeness and interactional implicatures. It is suggested here that a closer examination of the implicatures triggered by utterance-final conjunctive particles can provide an additional perspective on this long-standing debate about the nature of implicature and its relationship to linguistic form. 


\section{Appendix A: Symbols used in morphological gloss}

Acc $=$ accusative

$\mathrm{AtF}=$ attention focuser

Cont $=$ contrastive marker

Cop $=$ copula

$\mathrm{EM}=$ emotive mood marker

$\mathrm{FP}=$ (utterance) final particle

Gen $=$ genitive

Hon $=$ honorification

Imp $=$ imperative

$\mathrm{Neg}=$ negation

Nom $=$ nominative

Nomi $=$ nominaliser

Past $=$ past tense

Pol $=$ 'polite form'

Pot $=$ potential

Prog $=$ progressive

$\mathrm{Q}=$ question marker

Quot $=$ quotation

Tag $=$ tag question marker

$\mathrm{Te}=$ 'te-form'

Top $=$ topic marker

Vol $=$ volitional .

\section{Appendix B: Transcription conventions}

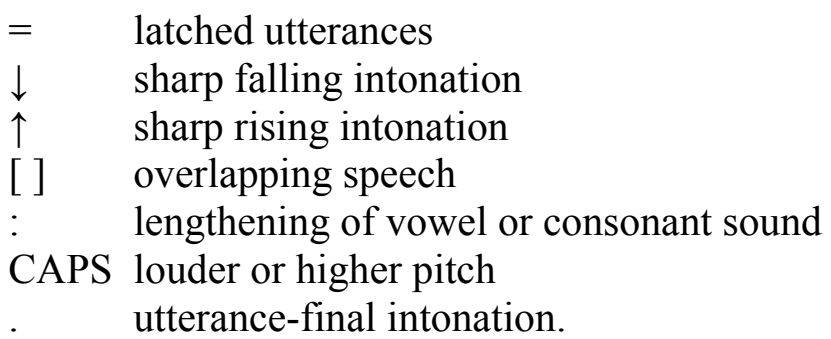

\section{References}

Aoki, Haruo, and Shigeko Okamoto (1988) Rules for Conversation Rituals in Japanese. Tokyo: Taishūkan.

Arundale, Robert (1999) An alternative model and ideology of communication for an alternative to politeness theory. Pragmatics 9.1: 119-154. 


\section{Michael Haugh}

Arundale, Robert (2004) Co-constituting face in conversation: An alternative to Brown and Levinson's politeness theory. Paper presented at the 90th Annual National Communication Association Conference, Chicago, Illinois.

Arundale, Robert (2005) Pragmatics, conversational implicature, and conversation. In K. Fitch and R. Sanders (eds.), Handbook of Language and Social Interaction. Mahwah, NJ: Lawrence Erlbaum, pp. 4163.

Arundale, Robert, and David Good (2002) Boundaries and sequences in studying conversation. In A. Fetzer and C. Meierkord (eds.), Rethinking Sequentiality. Linguistics Meets Conversational Interaction. Amsterdam: John Benjamins Publishing Company, pp. 121-150.

Bach, Kent (1999) The myth of conventional implicature. Linguistics and Philosophy 22: 327-366.

Bach, Kent (2006) The top 10 misconceptions about implicature. In B. Birner and G. Ward (eds.), Drawing the Boundaries of Meaning. Amsterdam: John Benjamins Publishing Company, pp. 21-30.

Bilmes, Jack (1985) "Why that now?" Two kinds of conversational meaning. Discourse Processes 8: 319-355.

Blakemore, Diane (1987) Semantic Constraints on Relevance. Oxford: Blackwell.

Blakemore, Diane (2002) Relevance and Linguistic Meaning. Cambridge: Cambridge University Press.

Blome-Tillmann, Michael (2008) Conversational implicature and the cancellability test. Analysis 68: 2.

Brown, Penelope, and Stephen Levinson (1987) Politeness. Some Universals in Language Usage. Cambridge: Cambridge University Press.

Burton-Roberts, Noel (2006) Cancellation and intention. Newcastle Working Papers in Linguistics 12/13: $1-12$.

Caffi, Claudia (1999) On mitigation. Journal of Pragmatics 31.7: 881-909.

Caffi, Claudia (2007) Mitigation. Oxford: Elsevier.

Carston, Robyn (2002) Thoughts and Utterances. The Pragmatics of Explicit Communication. Oxford: Blackwell.

Carston, Robyn (2004) Relevance theory and the saying/implicating distinction. In L. Horn and G. Ward (eds.), Handbook of Pragmatics. Oxford: Blackwell, pp.633-656.

Drew, Paul (1995) Conversation analysis. In J. Smith, R. Harré, and L. van Langenhove (eds.), Rethinking Methods in Psychology. London: Sage, pp. 64-79.

Fukushima, Tatsuya (2005) Japanese continuative conjunction ga as a semantic boundary marker. Language and Communication 25.1: 81-106.

Fujita, Naomi (2001) Politeness in interaction: A discourse approach to Japanese politeness markers. Unpublished Ph.D. dissertation, Columbia University.

Gauker, Christopher (2001) Situated inference versus conversational implicature. Nous 35: 163-189.

Grice, Paul (1967) Logic and Conversation. William James Lectures, Unpublished manuscript.

Grice, Paul (1989) Studies in the Way of Words. Cambridge, MA: Harvard University Press. 
Haugh, Michael (2002) The intuitive basis of implicature: Relevance theoretic implicitness versus Gricean implying. Pragmatics 12.2: 117-134.

Haugh, Michael (2005) The importance of "place" in Japanese politeness: Implications for cross-cultural and intercultural analyses. Intercultural Pragmatics 2.1: 41-68.

Haugh, Michael (2007a) The co-constitution of politeness implicature in conversation. Journal of Pragmatics 39.1: 84-110.

Haugh, Michael (2007b) Emic conceptulisations of (im)politeness and face in Japanese: Implications for the discursive negotiation of second language learner identities. Journal of Pragmatics 39.4: 657-680.

Haugh, Michael, and Carl Hinze (2003) A metalinguistic approach to deconstructing the concepts of 'face' and 'politeness' in Chinese, English and Japanese. Journal of Pragmatics 35.10: 1581-1611.

Hinds, John (1978) Conversational structure: An investigation based on Japanese interview discourse. In J. Hinds and I. Howard (eds.), Problems in Japanese Syntax and Semantics. Tokyo: Kaitakusha, pp. 79-121.

Hinds, John (1982) Japanese conversational structures. Lingua 57: 301-326.

Holmes, Janet (1984) Modifying illocutionary force. Journal of Pragmatics 8.3: 345-365.

Horn, Laurence (2004) Implicature. In L. Horn and G. Ward (eds.), The Handbook of Pragmatics. Oxford: Blackwell, pp. 3-28.

Hubbard, Mari (1988) Repetition and Ellipsis in Japanese Conversational Discourse: A Study of the Cognitive Domain of Conversational Interaction. Unpublished Ph.D. dissertation, The University of Wisconsin-Madison.

Ide, Sachiko (1989) Formal forms and discernment: Two neglected aspects of universals of linguistic politeness. Multilingua 8.2/3: 223-248.

Iguchi, Yoko (1998) Functional variety in the Japanese conjunctive particle kara 'because.' In T. Ohori (ed.), Studies in Japanese Grammaticalization. Cognitive and Discourse Perspectives. Tokyo: Kurosio, pp. 99-128.

Itani, Reiko (1992) Japanese conjunction kedo ('but') in utterance-final use: A relevance-based analysis. English Linguistics 9: 265-283.

Iten , Corine (2005) Linguistic Meaning, Truth Conditions and Relevance. Basingstoke, Hampshire: Palgrave Macmillan.

Kabaya, Hiroshi (1993) Taigū hyōgen ni okeru shōryaku [Ellipsis in polite expressions]. Nihongogaku 12.9: 27-33.

Kamio, Akio (1994) The theory of territory of information: The case of Japanese. Journal of Pragmatics 21.1: $67-100$

Kuno, Susumu (1978) Danwa no bunpō [Discourse grammar]. Tokyo: Taishūkan.

Lebra, Takie (1976) Japanese Patterns of Behaviour. Honolulu: University Press of Hawai'i.

Leech, Geoffrey (1983) Principles of Pragmatics. London: Longman.

Levinson, Stephen (1983) Pragmatics. Cambridge: Cambridge University Press.

Levinson, Stephen (2000) Presumptive Meanings. The Theory of Generalised Conversational Implicature. Cambridge, MA: MIT Press. 
Matsui, Tomoko (2002). Semantics and pragmatics of a Japanese discourse marker dakara (so/in other words): A unitary account. Journal of Pragmatics 24.7: 867-891.

Matsumoto, Yo (1988) From bound grammatical markers to free discourse markers. Berkeley Linguistics Society 14: 340-351.

Matsumoto, Yoshiko (1988) Reexamination of the universality of face: Politeness phenomena in Japanese. Journal of Pragmatics 12: 403-426.

Mastumoto, Yoshiko (1989) Politeness and conversational universals - observations from Japanese. Multilingua 8: 207-221.

Matsumoto, Yoshiko (2003) Discussion note: Reply to Pizziconi. Journal of Pragmatics 35.10/11: 15151521.

Maynard, Senko (1989) Japanese Conversation. Self-contextualisation through Structure and Interactional Management. Norwood, NJ: Ablex.

Mizutani, Osamu, and Nobuko Mizutani (1987) How to be Polite in Japanese. Tokyo: Japan Times.

Mori, Junko (1999) Negotiating Agreement and Disagreement in Japanese. Amsterdam: John Benjamins Publishing Company.

Nakayama, Toshihide, and Kumiko Ichihashi-Nakayama (1997) Japanese kedo: Discourse genre and grammaticalization. In: H. Sohn and J. Haig (eds.), Japanese Korean Linguistics Volume 6. Stanford, CA: CSLI Publications, pp. 607-619.

Obana, Yasuko (2000) Understanding Japanese. Tokyo: Kurosio.

Ohori, Toshio (1995) Remarks on suspended clauses: A contribution to Japanese phraseology. In M. Shibatani and S. Thompson (eds.), Essays in Semantics and Pragmatics. Amsterdam: John Benjamins Publishing Company, pp. 201-218.

Okamoto, Shigeko (1985) Ellipsis in Japanese Discourse. Unpublished Ph.D. dissertation, University of California, Berkeley.

Okazaki, Shoko (1994) Ellipsis in Japanese Conversational Discourse. Unpublished Ph.D. dissertation, Georgetown University.

Ooishi, Hatsutaro (1981) Hanashi kotoba to wa nani ka [What is spoken language?]. In Kotoba Shiriizu 12. Tokyo: Bunkachō, pp. 36-51.

Ooyama, Tetsuharu (1998) Poraitonesu no sutoratejī toshite no Nihongo bunmatsu hyōgen [Japanese sentence-final expressions as a politeness strategy]. In The Proceedings of the Dainikkai Shakaigengokagakkai Taikai [Second Sociolinguistic Sciences Society Conference], Kyoto University, Japan, pp. 5-10.

Potts, Christopher (2005) The Logic of Conventional Implicatures. Oxford: Oxford University Press.

Sadock, Jerry (1978) On testing for conversational implicature. In P. Cole (ed.), Syntax and Semantics, vol. 9. Pragmatics. New York: Academic Press, pp. 281-297.

Sanders, Robert (1999) The impossibility of a culturally contexted conversation analysis: On simultaneous, distinct types of pragmatic meaning. Research on Language and Social Interaction 32.1/2: $129-140$. 
Sasamoto, Ryoko (2008) Japanese discourse connectives dakara and sorede: A re-assessment of procedural meaning. Journal of Pragmatics 40.1: 127-154.

Saul, Jennifer (2002) Speaker meaning, what is said, and what is implicated. Nous 36.2: 228-248.

Sbisà, Marina (2001) Illocutionary force and degrees of strength in language use. Journal of Pragmatics 33.12: 1791-1814.

Sperber, Dan, and Deidre Wilson (1995) Relevance. Communication and Cognition (2 ${ }^{\text {nd }}$ edn.). Oxford: Blackwell.

Takahashi, T. (1993) Shōrayku ni yotte dekita jutsugo keishiki [Predicate forms created by ellipsis]. Nihongogaku 12.9: 18-26.

Tanaka, Hiroko (1999) Turn-taking in Japanese. A Study in Grammar and Interaction. Amsterdam: John Benjamins Publishing Company.

Tanaka, Liddia (2004) Gender, Language and Culture. A study of Japanese television interview discourse. Amsterdam: John Benjamins Publishing Company.

Toyoda, Miyuki, and Shunichi Ishihara (2003) The teaching of Japanese culture. In J. Lo Bianco and C. Crozet (eds.), Teaching Invisible Culture. Classroom Practice and Theory. Melbourne: Language Australia.

Uchito, Shoko (1997) Kanrensei riron ni okeru hanashikotoba ni arawareru shōryakubun no bunseki [An analysis of elliptical sentences occurring in speech from the perspective of relevance theory]. Bunkyo Daigaku Kokubun [Bunkyo University Journal of Japanese Literature] 26: 24-33.

Usami, Mayumi (2002) Discourse Politeness in Japanese Conversation: Some Implications for a Universal Theory of Politeness. Tokyo: Hituzi Syobo.

Weiner, Matthew (2006) Are all conversational implicatures cancellable? Analysis 66.2: 127-130.

Won, Ji-Eun (1999) Nichikan 'Chūto shūshi bun' no teineisa nitsuite [A comparative study of the politeness of unfinished utterances in Japanese and Korean]. Tsukuba Ooyōgengogaku Kenkyū [Tsukuba Research in Applied Linguistics] 6: 133-144.

Xie, Yun (2000) Irai Kōi: Nichichū Taishō Kenkyū [A Comparative Study of Requests in Japanese and Mandarin Chinese]. Unpublished Masters thesis, Tokyo University of Foreign Studies.

Xu, Xia Ling (2002) Bunmatsu 'kara' to 'karada' no imi yōhō [The meaning and usage of utterance-final kara and karada]. Gengo Bunka Ronshū [Studies in Language and Culture] (Nagoya University) 23.2: $67-79$.

Yamaguchi, Toshiko (2007). Japanese Language in Use. An Introduction. London: Continuum.

Yoneha Okazaki, Shoko (2003) Conversational styles and ellipsis in Japanese couples' conversations. In L. Thiesmeyer (ed.), Discourse and Silencing. Representation and the Language of Displacement. Amsterdam: John Benjamins Publishing Company, pp. 79-110.

Yotsukura, Lindsay (2003) Negotiating Moves: Problem Presentation and Resolution in Japanese Business Discourse. Amsterdam: Elsevier. 